Open Access

\title{
Role of mentoring in career adaptability and ambiguity tolerance of potential Nigerian entrepreneurs: the moderating effect of age
}

Omonigho Simon Umukoro* and David Efevogho Okurame

* Correspondence:

simon.umukoro@yahoo.com Department of Psychology, University of Ibadan, P.O. Box, 22400, U.I. Post Office, Ibadan, Nigeria

\begin{abstract}
This study examines age differentials in the predictive role of entrepreneurial mentoring on career adaptability and ambiguity tolerance among potential Nigerian entrepreneurs. A cross-sectional survey was adopted in obtaining relevant data for the study. The study participants were graduates who were participating in the National Youth Service Corp (NYSC) in Nigeria. This population forms a catchment group for entrepreneurship programmes in Nigeria. Their ages ranged from 19 to 30 years old; with 780 being male and 846 being female. Results showed that the interaction term of age and mentoring produced significant effect $(B=.174 ; p<.05)$ and accounted for a significant increase in career adaptability $\left(\Delta R^{2}=0.4 \% ; p<.05\right)$. The results imply that the effects of entrepreneurial mentoring on career adaptability were significant among both younger and older graduates; with a stronger effect being observed among the former $(B=.23, C l=.09$ to .17) than the latter $(B=.01$, $\mathrm{Cl}=.17$ to .24$)$. However, age did not moderate the effect of mentoring on ambiguity tolerance $(B=.033 ; p>.05)$. These results buttress appeals for incorporating adaptive mentorship models that cater for contextual factors (such as age differences) in entrepreneurship education aimed at enhancing specific modules of career adaptability and other important entrepreneurial traits.
\end{abstract}

Keywords: Entrepreneurship, Mentoring, Career adaptability, Ambiguity tolerance, Age, Graduates

\section{Introduction}

Entrepreneurship is increasingly a viable solution for tackling the problem of unemployment in developing nations (Asaju et al., 2014). Fresh graduates in Nigeria are regarded as potential entrepreneurs, thus both government agencies and non-governmental organizations continually provide several entrepreneurial schemes for fresh graduates. However, according the Global Entrepreneurship Index (2017) published by the Global Entrepreneurship and Development Institute (GEDI), Nigeria has recorded a significant drop in global rankings of entrepreneurship within Sub-Saharan Africa from 4th in 2016 to 12th in 2017. With entrepreneurship being touted to be a viable solution to the problems of unemployment in Nigeria, this drop in entrepreneurship ranking poses a new challenge for fresh graduates within the country. It may therefore

(C) The Author(s). 2018 Open Access This article is distributed under the terms of the Creative Commons Attribution 4.0 International License (http://creativecommons.org/licenses/by/4.0/), which permits unrestricted use, distribution, and reproduction in any medium, provided you give appropriate credit to the original author(s) and the source, provide a link to the Creative Commons license, and indicate if changes were made. 
be inferred that there is either an increase in the rate of business failure or a stagnation/decline in the start-up of more business ventures in the country. While there are various external factors that may impede the start-up and success of business, it has been argued that, ceteris paribus, the innate entrepreneurial skills of nascent entrepreneurs are key factors that determine the growth and sustainability of small and medium enterprises (SMEs) in Nigeria (Osalor, 2016).

Entrepreneurship involves the activity of setting up a business or businesses and taking on financial risks in the hope of making profit (Asaju, et al., 2014). A critical factor in the success of entrepreneurship ventures is the ability of entrepreneurs to utilize entrepreneurial skills and capabilities in meeting business challenges. However, Undiayaundeye \& Otu (2015) and Abdul (2018) identified lack of entrepreneurial skills among graduates as major determinants of failed entrepreneurial pursuits among business owners in Nigeria. Ojeifo (2013) also reported that majority of graduates from tertiary institutions in Nigeria have low entrepreneurial drive needed to thrive in the world of business. It has therefore been suggested that orientations towards entrepreneurship among fresh graduates may be dependent upon their adaptive skills and ability to effectively navigate through unanticipated transitions and risks inherent in entrepreneurship. Thus, behaviour modifications towards enhancing these traits may be beneficial in encouraging entrepreneurship among fresh graduates in Nigeria. In this regard, this study identifies career adaptability and ambiguity tolerance as necessary entrepreneurial skills for start-ups and survival of SMEs in Nigeria.

\section{Literature review}

Career adaptability is defined as the readiness to cope with unpredictable adjustments in career paths, which may be prompted by economic realities (Savickas, 2002). It is a psycho-social construct that denotes an individual's readiness and resources for coping with unanticipated career transitions. It focuses on the individual's ability to try other options. Existing research (Inkson et al., 2015; Perera \& McIlveen, 2017; Rudolph et al., 2017) has indicated that career adaptability is a sign of thriving which directly relates to entrepreneurship development. The importance of career adaptability in the journey through entrepreneurship has been underscored by renowned entrepreneurs. For instance, Bill Gates describes adaptability in entrepreneurship as being able to react or try another path when initial ideas hit a brick wall. If one has an unwavering commitment to a path (or an idea), then one will keep hitting a brick wall and never make progress.

Ambiguity tolerance represents a willingness to withstand uncertainty and mistakes as one explores new ideas, advocates unconventional or unpopular positions, or tackles extremely challenging problems without obvious solutions. According to Erten and Topkaya (2009) ambiguous situations can be of three different types: new situations, complex situations, and contradictory situations. These are, respectively, where there are not sufficient or nonexistent cues, where there are too many cues, and where cues are not easy to distinguish. Entrepreneurship is often characterized with uncertainties of expected outcomes. Thus, entrepreneurs necessarily learn to handle the risk and uncertainty inherent in starting and sustaining a business. In this regard, there are logical suppositions that entrepreneurial mentoring may have a profound influence on the variance in career adaptability and ambiguity tolerance of nascent entrepreneurs (Umukoro and Okurame, 2017). 
Nevertheless, these suppositions are premised on the assumption that business mentors possess a wealth of entrepreneurial experience and can often provide fresh and objective perspectives on entrepreneurship problems or challenges because they are not personally involved with the business and often have no conflicts of interest (Weinberg \& Lankau, 2010). Experienced entrepreneurs are therefore in a unique position to serve as conduits for the transmission of expert knowledge of entrepreneurial skills (Ilesanmi \& Lasisi, 2015). Business mentors' mastery of the entrepreneurial knowledge-space is borne out of their experience in the entrepreneurship space, which can serve as a rich resource for those with less experience. Such experts may also rely on various knowledge transmission and skill development strategies acquired from prior education as espoused by Ramayah et al. (2012), who showed that prior experience as an entrepreneur is highly correlated with entrepreneurial success.

Mentoring is a developmentally oriented interpersonal relationship that is typically between a more experienced individual (i.e., the mentor) and a less experienced individual (i.e., the protégé) (Okurame, 2007). A deeper understanding of the ways in which experienced entrepreneurs engage in mentoring activities with less experienced entrepreneurs allows for the identification of common educational strategies employed by these experts (Akpan et al., 2017). Further, an explication of the thought processes employed by experienced entrepreneurs in their interactions with those less experienced can lead to key insights into the mentoring process in the context of entrepreneurial education including the nature of the tacit knowledge (Polanyi, 2009) shared by the expert entrepreneur.

However, not many studies have directly examined the effects of mentoring in enhancing entrepreneurial traits of career adaptability, mentoring has been found to influence career oriented variable across various studies (Jyoti \& Sharma, 2017; Day \& Allen, 2004; Anafarta \& Apaydın, 2016; Jyoti \& Sharma, 2015; Parsa et al., 2016; Scott; 2010). Specifically, Kanten, Kanten and Ülker (2017) linked mentoring functions to career adaptability in a survey among 311 undergraduate students. Results of their study showed that mentoring functions, which is labeled as role modeling, have significant effects on career adaptability. Similarly, O'Mally and Antonelli (2016) found that students working with mentors demonstrated increased job-seeking self-efficacy and career adaptability.

Related studies by Tuna et al. (2014) on effects of career advising types and career adaptabilities showed that intellectual and affective advising types had a positive effect on career adaptabilities. Similar results on the relationship between career mentoring and career adaptabilities were obtained by Bimrose and Hearne (2012). According to these researchers, mentoring can be pivotal at turning points in individuals' lives. it supports and promotes both resiliency and career adaptability. In addition, they have suggested that through career mentoring, it leads them to understand their situation and consider best options for progressing in their future career. It may therefore be hypothesized that mentoring has a positive impact on career adaptability.

Research on the role of mentoring on ambiguity tolerance is also relatively scanty. However, outcomes of related studies, within similar contexts, may be drawn upon to make inferences about this relationship. For instance, Antonites \& Wordsworth (2009) provided a perspective on the influence of entrepreneurship education on risk tolerance. Their results suggested that entrepreneurs' ability to navigate successfully through 
risky ventures is highly dependent on effective entrepreneurship education. Similarly, Nieuwenhuizen and Kroon (2002) further emphasized the importance of including risk tolerance training in entrepreneurship mentoring programmes based on their study that found a strong relationship between willingness to take risks (risk tolerance) and the success of entrepreneurial training. Several dispositional variables have been found to influence risk-taking behavior in experimental settings, including self-confidence, perceived competence and mentorship (Caliendo et al., 2009; Fairlie, 2014). It is therefore expected that mentoring support may enhance the tolerance levels for risk and ambiguities in entrepreneurship among nascent entrepreneurs.

While mentoring may have a role to play in the variance of career adaptability and ambiguity tolerance, it may be necessary to understand how these relationships change under different conditions. Interestingly, an observation of mentoring relationship reveals that age and gender type in mentorship may have a significant impact on mentees' advancement, especially in career contexts (Okurame \& Balogun, 2005). This presents an argument for age as a moderator in the relationships between mentoring and entrepreneurial traits; suggesting that, across a broad array of mentor-protégé contexts and configurations, age shapes the functions and importance of relationships as highlighted by outcomes of related studies. There is a school of thought that younger persons are likely to be more receptive and malleable towards innovations in entrepreneurship (Poteat et al., 2009 Finkelstein et al., 2003; Rupp et al., 2006).

Moreover, from the standpoint of Taber's (1995) theory of prior learning, older persons are more likely to be rigid in business decision-making based on an accumulation of direct and indirect experiences garnered while growing, as opposed to younger persons, whose less experience, may provide a tabula rasa view on business perspectives. This has also been buttressed by studies that associate intuition and spontaneity in business decision-making among younger entrepreneurs (Umukoro \& Okurame, 2017 Matabooe et al., 2016). In Finkelstein et al. (2003) study on the role of both age and age diversity in mentorships, they found that the absolute age of the protégé in mentoring influenced career mentoring provided, characteristics of the mentorship, and perceptions of mutual learning. Their results showed that older protégés, on average, experienced less career-related mentoring than younger protégés and had shorter relationships with their mentors. This finding may reflect the belief that older protégés may not require career related mentoring as much as a younger protégé. However, Deering (2010) found contrary results showing that age difference does not have any aversive effects on the processes found in mentoring relationships.

\section{Hypotheses}

Based on theoretical assumptions and review of prior research on mentoring relationships in a variety of related contexts, this study is guided by the following hypotheses.

\section{Hypothesis 1}

The significant effect of entrepreneurial mentoring on career adaptability will be moderated by age, such that the impact of entrepreneurial mentoring will be higher among younger graduates than older graduates. 


\section{Hypothesis 2}

The significant effect of entrepreneurial mentoring on ambiguity tolerance will be moderated by age, such that the impact of entrepreneurial mentoring will be higher among younger graduates than older graduates.

\section{Theoretical framework}

The theoretical suppositions of this study are anchored on Harré and van Langenhove (1999) positioning theory. Harré and van Langenhove (1999) state positioning can be understood as the discursive construction of personal stories and experiences that make a person's actions intelligible and relatively determinate as social acts. This recognizes the act of positioning as a communicated process that clarifies the particular 'role' (role is the static description) or interactive relation between those involved. Positioning can allow for mutual determination for interaction or can instigate a dialogue or several dialogues in which the 'roles' presented are negotiated and redefined. This concept is important to understand the process of developing entrepreneurial abilities because it emphasizes the social interaction that can affect the actions taken by the nascent entrepreneur. Applying the concept of negotiated rights and duties allows for exploration of how relationships are formed and developed over time, including understanding of relationship formation and change (Bullough Jr. and Draper, 2004).

According to Bandura (1997), behavior is learned not only through observation of others, but then through practicing the actions required to perform the behavior (Bratton et al., 2010). These processes include observational learning, imitation, and social modeling. Individuals observe and take note of the behavior of others, perceived as knowledgeable or credible, and then practice the behavior and experience the consequences of the behavior. Bandura's theories relate to Vygotsky's Principle which states that behavior is developed both on a social level and on an individual level (Vygotsky, 1978), initiating with the social level, such that behaviors "originate as actual relationships between individuals." Expanding upon Vygotsky, the focus on the contribution of the others in the social interaction can be understood as a mentor-mentee relationship where the less skilled mentee attempts to accomplish a task, supported by the mentor. If the mentee cannot perform the task to completion, the mentor helps to accomplish the task, in a way that the mentee can observe and copy the mentor's actions for future tasks (Harré \& van Langenhove, 1999).

In relation to this study career dynamics within entrepreneurial contexts are considered to be a function of social contexts and situations, including role-sets and patterns of social interaction leading to entrepreneurial abilities (Pruett et al., 2009) in relation to specific resources such as career adaptability and ambiguity tolerance. In this study, the researchers propose a role-set definition that includes all types of mentors including the family members, financers, partners, other advisors and coaches. Thus, positioning theory provides a perspective upon how career adaptability and ambiguity tolerance can be facilitated through interaction with a role-set. Conversations between the nascent entrepreneur and his/her role-set allows for discussion and negotiation of rights and duties regarding the expectations of a role, and the associated actions that can therefore be taken. The nascent entrepreneurs observe, imitate and model actors in the role-set in balance with testing and promoting their own beliefs and motivations. 


\section{Methods}

\section{Participants}

Using a structured questionnaire, a cross-sectional survey was adopted to obtain data for the study. Participants were drawn from an estimated population of 16,402 corps members (Batch A) in the six National Youth Service Corp ${ }^{1}$ (NYSC) orientation camps within the six states ${ }^{2}$ that make up southwestern, Nigeria. This population forms a catchment group for potential entrepreneurs in Nigeria and reflects a microcosm of socio-cultural diversities among Nigerian youths. Adopting the Krejcie and Morgan (1970) sample size determination formula, a representative sample was obtained from each NYSC camp, in relation to the total number of youth corps members deployed to each of the camps. Based on the sample sizes obtained from the camps in Oyo $(n=351)$, Lagos $(n=354)$, Ogun $(n=327)$, Ondo $(n=320)$, Osun $(n=310)$, and Ekiti $(n=313)$; a total of 1975 copies of the questionnaire were distributed across the six NYSC camps; however only 1626 of the retrieved questionnaires were valid to make up the final sample for the study (see Fig. 1). The age of the

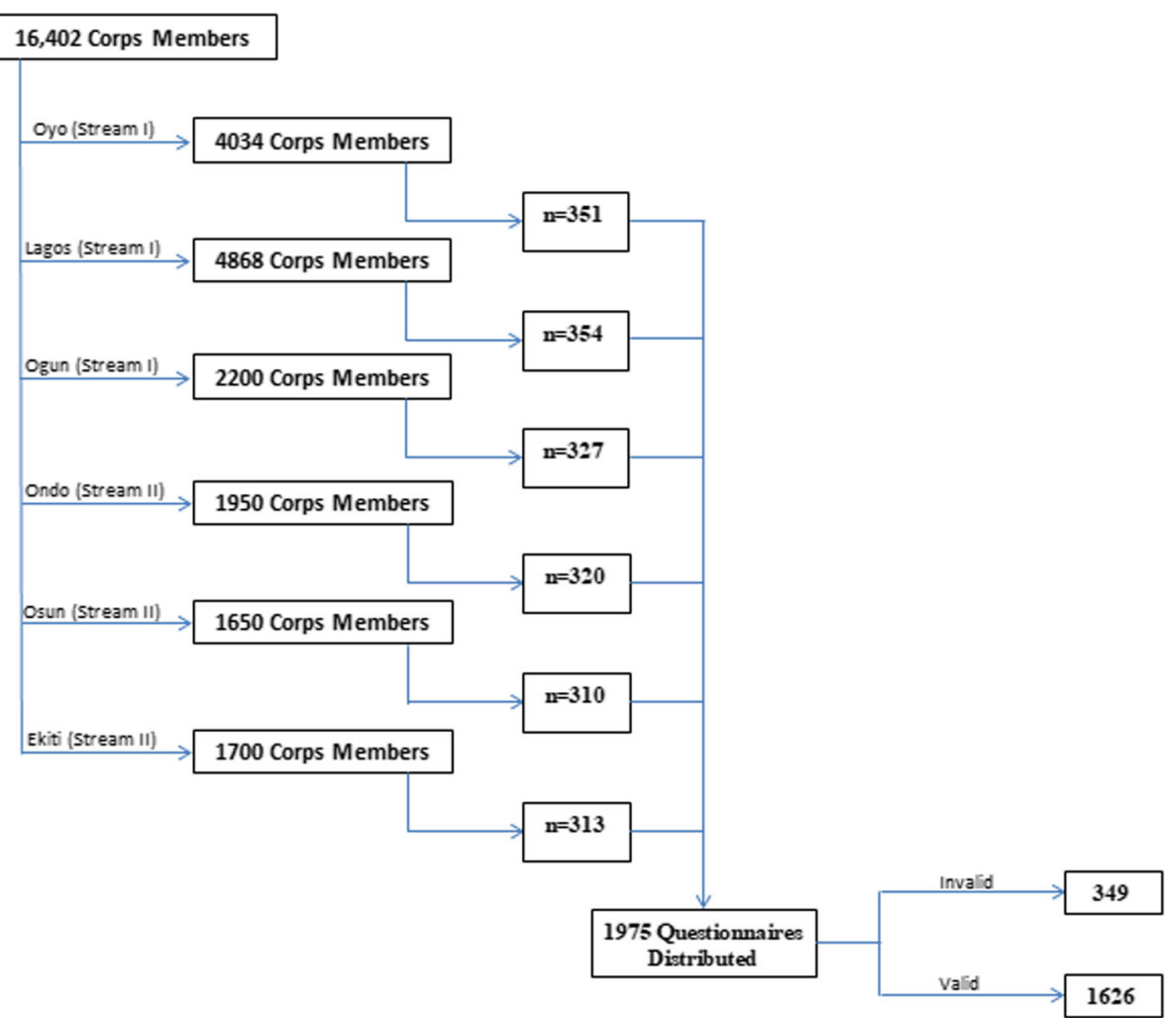

Fig. 1 Flow Chart Showing Sampling Procedure. Figure illustrates the sampling procedure used in obtaining the sample size for the study. Participants were drawn from an estimated population of 16,402 corps members (Batch A) in the six NYSC orientation camps within the states (Oyo, Lagos, Ogun, Ondo Osun, Ekiti) in southwestern, Nigeria. Based on the total number of corps members in each of the selected camps, the Krejcie and Morgan (1970) sample size determination formula was used to obtain a representative sample for each camp. A systematic sampling technique was then used to select participants for the study by including every $n^{\text {th }}$ corps member of the sampling interval. A total of 1975 copies of the questionnaire were distributed across the six NYSC camps; however only 1626 of the retrieved questionnaires were valid to make up the final composite sample for the study 
participants ranged from 19 years to 30 years old with 780 being male and 846 being female. In terms of their graduating tertiary institution, 692 (42.6\%) of the participants were from federal universities, $434(26.7 \%)$ of them were from state universities, 128 (7.9\%) of them were from federal polytechnics, 166 (10.2\%) of them were from state polytechnics while $206(12.7 \%)$ of them were from private tertiary institutions.

\section{Measures}

\section{Demographic data}

Age was measured on a continuum; however, the inclusion of age as a moderator in the study necessitated a dichotomized measure of age into 'younger' and 'older' participants. The mean age ( 24 years) was used as the norm for the dichotomy. Sex and type of graduating institution were measured as nominal variables; however their inclusion in a regression model as covariates required them to be recoded as dummy variables.

\section{Career adaptability}

Career adaptability was measured using Savickas' Career Adaptability Scale (2002). The scale measures the readiness of an individual to cope with transitions in future career choices. All items are measured on a 5-point likert-type scale ranging from "1: strongly disagree" to "5: strongly agree". High scores depict higher levels of career adaptability while low scores depict lower levels of career adaptability. The scale has been validated in several studies (Hirschi, 2009; Ito \& Brotheridge, 2005; Klehe, Zikic, Van Vianen \& De Pater, 2011; Ebenehi, Rashid \& Bakar, 2016) with Cronbach's alpha ranging from 0.6 to 0.8 . In this study, a Cronbach alpha of 0.712 was obtained for the scale.

\section{Ambiguity tolerance}

Ambiguity tolerance was measured using The Multiple Stimulus Types Ambiguity Tolerance Scale-II (MSTAT-II; McLain, 2009). The MSTAT-II is a 13-item measure designed to measure an individual's cognitive tolerance range (aversion to attraction) for situations that are unfamiliar, insoluble, or complex. The MSTAT-II measures the participants' degree of ambiguity tolerance based on five stimulus types: Items are structured as five-point likert-type responses ranging from " $1=$ strongly disagree" to " 5 = strongly agree". Classification of participants into high ambiguity tolerance or low ambiguity tolerance is determined by a median split of total scores; scores ranging between 13 and 38 indicates a lower ambiguity tolerance while scores between 39 and 65 indicate a higher ambiguity tolerance. McLain (2009) reported an internal consistency reliability of .83 while Ogunleye and Osagu (2014) also obtained a Cronbach alpha of 0.6 for the scale. In this study, a Cronbach alpha of 0.788 was obtained for the scale.

\section{Entrepreneurial mentoring}

Entrepreneurial mentoring was measured using a modified version of a 15 -item mentoring functions scale by Okurame (2012) The 15-item scale measures the extent of formal or informal mentoring support that protégés feel they have received from their 
mentors in entrepreneurship issues using a 5-point likert-type scale of $1=$ "strongly disagree" to 5 = "strongly agree." Examples of some of the items in the modified version include "I have a mentor who gives me competent advice about handling business opportunities", 'I have a mentor whose entrepreneurship skills have influenced my desire to build similar skills'. Higher scores indicate higher levels of mentorship support while low scores indicate lower levels of mentorship support. An alpha coefficient and least item-total correlation of .89 and .259 respectively were obtained by the original author of the scale. In this study, a Cronbach alpha of 0.95 was obtained for the scale.

\section{Analytical procedure}

For analyses of data, the study employed a moderated multiple regression using PROCESS macro (Hayes, 2013) which analyzes direct and conditional effects of moderators in a model. It entails the addition of an interaction term (mentoring and age) in a linear multiple regression to determine the moderating effect of age in the model. In the regression models, the effects of sex and type of graduating institution were controlled for as covariates.

\section{Results}

Hypothesis one

Hypothesis one stated that the significant effect of entrepreneurial mentoring on career adaptability will be moderated by age, such that the impact of entrepreneurial mentoring will be higher among younger graduates than older graduates. Results from Table 1 show that the interaction term produced significant effect $(\mathrm{B}=.174 ; p<.05)$ and accounted for a significant increase in $\mathrm{R}^{2}$ by $0.4 \%$. Overall, the model explained $10.6 \%$ of career adaptability. The results imply that age moderated the effect of entrepreneurial mentoring on career adaptability.

Table 2 shows the conditional effects of entrepreneurial mentoring at the dichotomized levels of age.

Table 1 Regression model showing moderation effects of age on the predictive influence of entrepreneurial mentoring on career adaptability

\begin{tabular}{|c|c|c|c|c|c|c|c|}
\hline & & \multirow[t]{2}{*}{$\mathrm{B}$} & \multirow[t]{2}{*}{ SE } & \multirow[t]{2}{*}{$\mathrm{T}$} & \multirow[t]{2}{*}{$P$} & \multicolumn{2}{|l|}{$95 \% \mathrm{Cl}$} \\
\hline & & & & & & $\mathrm{LLCl}$ & ULCI \\
\hline \multirow[t]{5}{*}{1} & Constant & 38.998 & .884 & 44.129 & $<.05$ & 37.265 & 40.731 \\
\hline & Sex & .5502 & .3440 & 1.5996 & $>.05$ & -.1245 & 1.2249 \\
\hline & Type of Graduating Institution & .0449 & .1204 & .3726 & $>.05$ & -.1914 & .2811 \\
\hline & Entrepreneurial Mentoring & 2.181 & .013 & 13.866 & $<.05$ & .155 & .207 \\
\hline & Age & -.442 & .348 & -1.272 & $>.05$ & -1.125 & .240 \\
\hline \multirow[t]{4}{*}{2} & Constant & 45.250 & 2.412 & 18.758 & $<.05$ & 40.519 & 49.982 \\
\hline & Entrepreneurial Mentoring & 2.064 & .044 & 1.461 & $<.05$ & -.022 & .150 \\
\hline & Age & -4.407 & 1.465 & -3.007 & $<.05$ & -7.281 & -1.533 \\
\hline & $\begin{array}{l}\text { Entrepreneurial Mentoring } \\
\text { X Age }\end{array}$ & .174 & .026 & 2.785 & $<.05$ & .022 & .126 \\
\hline
\end{tabular}

DV: Career Adaptability, Model Summary: $\mathrm{R}^{2}=.106, \mathrm{~F}_{(5,1618)}=96.148 ; p<.05, \Delta \mathrm{R}^{2}$ due to interaction: $\Delta \mathrm{R}^{2}=.004$,

$\mathrm{F}_{(1,1618)}=7.754 ; p<.05$ 
Table 2 Post hoc test for conditional effects of entrepreneurial mentoring at levels of age

\begin{tabular}{lllllll}
\hline Age & Effect & S.E & $T$ & $P$ & LLCl & ULCl \\
\hline Younger & .2379 & .0203 & 12.8052 & $<.05$ & .0981 & .1776 \\
Older & .0116 & .0170 & 6.4298 & $<.05$ & .1782 & .2449 \\
\hline
\end{tabular}

Results showed that the effects of entrepreneurial mentoring on career adaptability were significant at both levels of age. However, a stronger effect was observed among younger graduates $(\mathrm{B}=.23, \mathrm{CI}=.09$ to .17$)$ than older graduates $(\mathrm{B}=.01, \mathrm{CI}=.17$ to .24). This implies that entrepreneurial mentoring is likely to be more potent in enhancing career adaptability among younger graduates compared to their older counterparts. Thus, hypothesis one was accepted.

\section{Hypothesis two}

Hypothesis two stated that the significant effect of entrepreneurial mentoring on ambiguity tolerance will be moderated by age, such that the impact of entrepreneurial mentoring will be higher among younger graduates than older graduates. Results from Table 3 show that the interaction term produced a non-significant effect $(B=.033$; $p>.05$ ) and accounted for an insignificant increase in $\mathrm{R}^{2}$ by $0.1 \%$. Overall, the model explained $3.7 \%$ of ambiguity tolerance. The results imply that age did not moderate the effect of entrepreneurial mentoring on ambiguity tolerance. Thus, hypothesis two was rejected.

\section{Discussion}

The first model of hypothesis one showed that career adaptability was predicted by entrepreneurial mentoring. The result implies that through entrepreneurial mentoring, the adaptive abilities of graduates can be enhanced for advancement along chosen entrepreneurial careers. The plausibility of this outcome may stem from business mentors' ability to demonstrate the importance of career adaptability in practical terms. Thus, mentees are able to understand and identify adaptive situations and strategies in

Table 3 Regression model showing moderation effects of age on the predictive influence of entrepreneurial mentoring on ambiguity tolerance

\begin{tabular}{|c|c|c|c|c|c|c|c|}
\hline & & \multirow[t]{2}{*}{ B } & \multirow[t]{2}{*}{ SE } & \multirow[t]{2}{*}{$\mathrm{T}$} & \multirow[t]{2}{*}{$P$} & \multicolumn{2}{|l|}{$95 \% \mathrm{Cl}$} \\
\hline & & & & & & $\mathrm{LLCl}$ & ULCI \\
\hline \multirow[t]{5}{*}{1} & Constant & 32.910 & 1.002 & 32.832 & $<.05$ & 30.944 & 34.876 \\
\hline & Sex & 6851 & .3550 & 1.9297 & $>.05$ & -.0113 & 1.3815 \\
\hline & Type of Graduating Institution & .0264 & .1246 & .2116 & $>.05$ & -.2181 & .2708 \\
\hline & Entrepreneurial Mentoring & .116 & .015 & 7.825 & $>.05$ & .087 & .145 \\
\hline & Age & .042 & .395 & .108 & $>.05$ & -.732 & .817 \\
\hline \multirow[t]{4}{*}{2} & Constant & 35.736 & 2.742 & 13.035 & $<.05$ & 30.359 & 41.114 \\
\hline & Entrepreneurial Mentoring & .063 & .050 & 1.262 & $>.05$ & -.035 & .161 \\
\hline & Age & -1.750 & 1.666 & -1.051 & $>.05$ & -5.017 & 1.517 \\
\hline & $\begin{array}{l}\text { Entrepreneurial Mentoring } \\
\text { x Age }\end{array}$ & .033 & .030 & 1.108 & $>.05$ & -.026 & .092 \\
\hline
\end{tabular}

DV: Ambiguity Tolerance, Model Summary: $\mathrm{R}^{2}=.037, \mathrm{~F}_{(3,1621)}=30.887 ; p>.05, \Delta \mathrm{R}^{2}$ due to interaction: $\Delta \mathrm{R}^{2}=.001$, $\mathrm{F}_{(1,1620)}=1.227 ; p>.05$ 
business from practical illustrations and lived experiences of business mentors. Practical illustrations of the how nascent entrepreneurs enhance career adaptability through a mentor's expertise may include; receiving critical feedback in key areas, such as communications, interpersonal relationships, technical abilities, change management, and leadership skills; developing a sharper focus on details and cues in business; learning specific skills and knowledge that are relevant to adaptive strategies; building career enhancing networks with relevant entities; developing proactive capabilities for making business related decisions; and having a friendly ear with which to share frustrations as well as successes.

In support for this assertion, O'Mally and Antonelli (2016) showed that final year college students working with mentors demonstrated increased job-seeking self-efficacy, career adaptability, and significant gains in job-hunting assertiveness compared to those receiving only traditional job-search resources. Related studies by Tuna et al. (2014) on effects of career advising types and career adaptabilities showed that intellectual and affective advising types had a positive effect on career adaptabilities. Kanten, Kanten and Ülker (2017) also reported significant positive effects of mentoring functions on career adaptability of potential entrepreneurs. Similar results on the relationship between career mentoring and career adaptabilities were obtained by Bimrose and Hearne (2012), showing that mentoring can be pivotal at turning points in individuals' lives, as it supports and promotes both resiliency and career adaptability. Thus the importance of entrepreneurial mentoring in enhancing adaptive abilities was aptly highlighted by this result.

The second model of hypothesis one identified the moderating effect of age in the link between entrepreneurial mentoring and career adaptability. Results showed that age emerged as a significant moderator, such that entrepreneurial mentoring is much more effective in predicting career adaptability among younger mentees than older mentees. This implies that younger mentees are likely to benefit more from entrepreneurial mentoring in relation to acquiring adaptive abilities in entrepreneurial career paths. Taber's (1995) theory of prior learning as an epistemological block may explain the differentials that age of mentees' has in a mentoring relationship. Based on Taber's perspective, personal experiences of older persons prior to novel teachings might act as a block to effective learning of novel ideas. In relation to the outcomes of this study, preconceptions that older persons have prior to entrepreneurial mentoring may not be as amenable as the untainted learning slate of younger persons. Finkelstein et al. (2003) also found that older protégés on average experienced less career-related mentoring than younger protégés; while Matabooe et al. (2016) identified age as a relational-based condition for effective mentoring. Thus, older individuals may fail to fully benefit from relationshps with competent mentors.

Results of the second hypothesis showed that entrepreneurial mentoring did not predict ambiguity tolerance; and age did not have any moderating role in the model. While some studies (Antonites \& Wordsworth, 2009; Nieuwenhuizen and Kroon, 2002) have suggested that individuals could be mentored in managing ambiguities in business, it is quite instinctive for individuals to avoid taking uncalculated risks. Even seasoned entrepreneurs often exhaust possible alternatives and extrapolations before taking uncalculated risks in business. Thus, this natural instinct may deflect the potency of any form of entrepreneurial mentoring directed at enhancing tolerance for ambiguities in 
business. However, it has established that being able to make business decisions in relatively unfamiliar market situations may be fostered by knowledge and experience garnered from formal and informal mentoring relationship (Holm et al., 2013). An experienced entrepreneur is therefore in a position to offer mentoring support on issues of business uncertainties based on personal experiences.

\section{Conclusion}

While literature has established the importance of career adaptabilities in facilitating success outcomes in entrepreneurship, results of this study have shown that entrepreneurial mentoring is a key facilitator of career adaptability. This is because, through mentoring relationships, business mentors are able to equip young entrepreneurs with the fundamentals to help them navigate through the challenges and vicissitudes inherent in business start-ups and growth. The results also point to the potency of entrepreneurial mentoring towards younger protégés. These results therefore buttress appeals for incorporating intensive and comprehensive entrepreneurial mentoring in the structure of entrepreneurship education being taught in all categories of tertiary institutions in Nigeria. Furthermore, such training should be adapted to suit the age differences of aspiring entrepreneurs, and include context specific modules of career adaptability and other important entrepreneurial traits.

\section{Contribution to knowledge}

The outcomes of this study provide insight into how age moderates the predictive value of entrepreneurial mentoring on career adaptability; which highlights the need for incorporating adaptive mentorship models in entrepreneurship education. With adaptive mentorship, mentors adjust their mentoring responses to match contextual factors (such as age differences) that may affect protégés' learning outcomes and task-specific development level while coaching them in their learning setting. As Ralph and Walker (2010) have shown, many of these contextual factors cannot be changed by the mentor, but the mode of mentoring can be. Thus, future studies on mentoring relationships should lay more emphasis on dimensions of adaptive mentoring and its impact in actual business settings.

\section{Endnotes}

${ }^{1}$ The National Youth Service Corps is a scheme for Nigerian graduates from universities, polytechnics and other local or foreign degree awarding institutions. The scheme is established to promote the ideals of national unity and promote national economic, development through mobility of labour in the formal and informal sectors. The service commences with an "orientation" period of approximately three weeks spent in a military controlled "camp" away from family and friends. There is also a "passing out ceremony" at the end of the three weeks orientation camp after which corps members are posted to their Place of Primary Assignment (PPA). The duration for the service is one year after which the youths are given a certificate which is a requirement for employment in the country.

${ }^{2}$ Oyo, Lagos, Ogun, Ondo, Osun, Ekiti, 


\section{Abbreviations}

GEDI: Global entrepreneurship and development institute; NYSC: National youth service corps; SME: Small and medium enterprises; SPSS: Statistical package for social sciences

\section{Acknowledgements}

"Not applicable" in this section.

\section{Funding}

The research was self-funded through the institutional platform of the University of Ibadan as part of the requirements for a Ph.D. in Industrial and Organizational Psychology.

\section{Availability of data and materials}

The datasets used and/or analysed during the current study are available from the corresponding author (with permission from the co-author) on reasonable request.

\section{Authors' contributions}

UOS (Researcher). Carried out the fieldwork and data analysis. Carried out the write-up for the research. ODE (Academic Supervisor). Carried out supervisory role for the research. Reviewed the final version of the manuscript. Both authors read and approved the final manuscript.

\section{Competing interests}

The authors declare that they have no competing interests.

\section{Publisher's Note}

Springer Nature remains neutral with regard to jurisdictional claims in published maps and institutional affiliations.

\section{Received: 14 May 2018 Accepted: 7 November 2018}

Published online: 30 November 2018

\section{References}

Abdul, O.E. (2018).Entrepreneurial skills and growth of Small and Medium Enterprise (SMEs): A comparative analysis of Nigerian entrepreneurs and Minority entrepreneurs in the UK. MPRA Paper No. 86751. https://mpra.ub.uni-muenchen.de/ $86751 /$

Akpan, J. W., Owhor, A. G., \& Nsikan, E. J. (2017). Workplace mentoring strategies and sustainable commitment of university teaching hospital staff in south-south region of Nigeria. Global Journal of Medical Research, 17(7), 26-34.

Anafarta, A., \& Apaydin, Ç. (2016). The effect of faculty mentoring on career success and career satisfaction. International Education Studies, 9(6), 22-31.

Antonites, A. J., \& Wordsworth, R. (2009). Risk tolerance: A perspective on entrepreneurship education. Southern African Business Review, 13(3), 69-85.

Asaju, K., Arome, S., \& Anyio, S. (2014). The rising rate of unemployment in Nigeria; socio-economic and political implications. Global Business and Economic Research Journal, 3(2), 12-32.

Bandura, A. (1997). Self-efficacy: The exercise of control. New York: W.H. Freeman and Company.

Bimrose, J., \& Hearne, L. (2012). Resilience and career adaptability: Qualitative studies of adult career counseling. Journal of Vocational Behavior, 81, 338-344.

Bratton, J., Sawchuk, P., Forshaw, C., Callinan, M., \& Corbett, M. (2010). Work and organizational behaviour. Basingstoke: Palgrave Macmillan.

Bullough, R. V., Jr., \& Draper, R. J. (2004). Making sense of a failed triad: Mentors, university supervisors, and positioning theory. Journal of Teacher Education, 55(5), 407-420.

Caliendo, M., Fossen, F. M., \& Kritikos, A. S. (2009). Risk attitudes of nascent entrepreneurs - New evidence from an experimentally-validated survey. Small Business Economics, 32(2), 153-167.

Day, R., \& Allen, T. D. (2004). The relationship between career motivation and self-efficacy with protégé career success. Journal of Vocational Behavior, 64, 72-91.

Deering, K. (2010). The Contributions and Affects of Age on Mentoring Relationships within an Academic Setting. A dissertation for Master's Degree of Science in Applied Psychology at the University of Canterbury

Ebenehi, A. S., Rashid, A. M., \& Bakar, A. R. (2016). Predictors of Career Adaptability Skill among Higher Education Students in Nigeria. International Journal for Research in Vocational Education and Training, 3(3), 212-229.

Erten, I. H., \& Topkaya, E. Z. (2009). Understanding tolerance of ambiquity of EFL learners in reading classes at tertiary level. Novitas-ROYAL, 3(1), 29-44.

Fairlie, R. (2014). Entrepreneurship Training, Risk Aversion and Other Personality Traits: Evidence from a Random Experiment. UC Santa Cruz: Working Paper Series https://escholarship.org/uc/item/9x83w5k4.

Finkelstein, L., Allen, T., \& Rhoton, L. (2003). An examination of the role of age in mentoring relationships. Group Organization and Management, 28(2), 249-281.

Harré, R., \& van Langenhove, L. (Eds.). (1999). Positioning theory. Malden, MA: Blackwell Publishers.

Hayes, A. F. (2013). Introduction to Mediation, Moderation, and Conditional Process Analysis: A Regression-Based Approach. New York, NY: The Guilford Press.

Hirschi, A. (2009). Career adaptability development in adolescence: Multiple predictors and effect on sense of power and life satisfaction. Journal of Vocational Behaviour, 74, 145-155.

Holm, H. J., Opper, S., \& Nee, V. (2013). Entrepreneurs under uncertainty: An economic experiment in China. Management Science, 59(7), 1671-1687. 
Ilesanmi, O. A., \& Lasisi, F. A. (2015). Role of mentoring in business development in Nigeria. Global Journal of Human Resource Management, 3(3), 17-38.

Inkson, K., Dries, N., \& Arnold, J. (2015). Understanding careers: The metaphors of working lives. London: Sage.

Ito, J. K., \& Brotheridge, C. M. (2005). Does supporting employee's career adaptability lead to commitment, turnover, or both? Human Resource Management, 44(1), 5-19.

Jyoti, J., \& Sharma, P. (2015). Impact of mentoring functions on career development: moderating role of mentoring culture and mentoring structure. Glob. Bus. Rev., 16, 700-718.

Jyoti, J., \& Sharma, P. (2017). Empirical investigation of a moderating and mediating variable in between mentoring and job performance: A structural model. Journal of Work and Organizational Psychology, 33, 55-67.

Kanten, S., Kanten, P., \& Ulker, F. (2017). The Effects of Mentoring Functions on Career Adaptabilities and Career Self-Efficacy: the Role of Career Optimism. European Journal of Multidisciplinary Studies, 2(7), 259272.

Klehe, U. C., Zikic, J., Van Vianen, A. E. M., \& De Pater, I. (2011). Career adaptability, turnover and loyalty during organizational downsizing. Journal of Vocational Behavior, 217-229.

Krejcie, R. V., \& Morgan, D. W. (1970). Determining sample size for research activities. Educational and Psychological Measurement, 30(3), 607-610.

Matabooe, M. J., Venter, E., \& Rootman, C. (2016). Understanding relational conditions necessary for effective mentoring of black-owned small businesses: A south African perspective. Acta Commercii, 16(1), a327.

McLain, D. L. (2009). Evidence of the properties of an ambiguity tolerance measure: The multiple stimulus types ambiguity tolerance scale-II. Psychological Reports, 105, 975-988.

Nieuwenhuizen, C., \& Kroon, J. (2002). Identification of entrepreneurial success factors to determine the content of entrepreneurship subjects. South African Journal of Higher Education, 16(3), 157-166.

Ogunleye, A. J., \& Osagu, J. C. (2014). Self-Efficacy, Tolerance for Ambiguity and Need for Achievement as Predictors of Entrepreneurial Orientation among Entrepreneurs in Ekiti State, Nigeria. European Journal of Business and Management, 6(17), 240-250

Ojeifo, S. A. (2013). Entrepreneurship education in Nigeria: A panacea for youth unemployment. Journal of Education and Practice, $4(6)$.

Okurame, D. E. (2007). Perceived mentoring functions: Does mentor's gender matter? Women in Management Review, 22(5), $418-427$.

Okurame, D. E. (2012). Linking work-family conflict to career commitment: The moderating role of gender and mentoring. Journal of Career Development, 39(5), 423-442.

Okurame, D. E., \& Balogun, S. K. (2005). Role of informal mentoring in the career success of first-line Bank managers: A Nigerian case study. Career Development International, 10(7), 512-521.

O'Mally, J., \& Antonelli, K. (2016). The effect of career mentoring on employment outcomes for college students who are legally blind. Journal of Visual Impairment \& Blindness, 110(5), 295-307.

Osalor, P. (2016). Entrepreneurial revolution; the way forward Nigeria. Vanguard News. Vanguardngr.com.

Parsa, B., Parsa, P., \& Parsa, N. (2016). Mediation effect of self-efficacy on the relationship between mentoring function and career advancement among academics in Iran. Global Journal of Health Science, 8(10), 295-306.

Perera, H. N., \& Mcllveen, P. (2017). Profiles of career adaptivity and their relations with adaptability, adapting, and adaptation. Journal of Vocational Behavior, 98, 70-84.

Polanyi, M. (2009). The tacit dimension (A. Sen Ed.). Chicago, IL; London, England: University of Chicago Press.

Poteat, L. F., Shockley, K. M., \& Allen, T. D. (2009). Mentor-protégé commitment fit and relationship satisfaction in academic mentoring. Journal of Vocational Behaviour, 74, 332-337.

Pruett, M., Shinnar, R., Toney, B., Llopis, F., \& Fox, J. (2009). Explaining entrepreneurial intentions of university students: A crosscultural study. International Journal of Entrepreneurial Behaviour \& Research, 15(6), 571-594.

Ralph, E., \& Walker, K. (2010). Enhancing Mentors' effectiveness: The promise of the adaptive mentorship model. McGill Journal of Education, 45(2), 205-218.

Ramayah, T., Ahmad, N. H., \& Char-Fei, T. H. (2012). Entrepreneur education: Does prior experience matter. Journal of Entrepreneurship Education, 15, 65-82.

Rudolph, C. W., Lavigne, K. N., \& Zacher, H. (2017). Career adaptability: A meta-analysis of relationships with measures of adaptivity, adapting responses, and adaptation results. Journal of Vocational Behavior, 98, 17-34.

Rupp, D. E., Vodanovich, S. J., \& Crede, M. (2006). Age bias in the workplace: The impact of ageism and casual attributions. Journal of Applied Social Psychology, 36(6), 1337-1364.

Savickas, M. L. (2002). Career construction: A developmental theory of vocational behavior. In D. Brown (Ed.), \& Associates (Eds.) Career choice and development (4th ed., pp. 149-205). San Francisco, CA: Jossey-Bass.

Taber, K. S. (1995). An analogy for discussing progression in learning chemistry. School Science Review, 76(276), 91-95.

Tuna, M., Kanten, P., Yeşiltaş, M., Kanten, S., \& Alparslan, A. M. (2014). The effect of academic advising on career adaptabilities: A study among tourism and hotel management students. The Macrotheme Review, 3(8), 139-155.

Umukoro, O. S., \& Okurame, D. E. (2017). Culture-specific perspectives of age and gender disparities in entrepreneurial intuition. Global Journal of Human Social Sciences, 17(8), 12-21.

Undiayaundeye, A. (2015). Entrepreneurship skills acquisition and the benefits amongst the undergraduate students in Nigeria. European Journal of Social Sciences, 4(1)

Vygotsky, L. S. (1978). Mind in society. Cambridge, MA: MIT Press.

Weinberg, F. J., \& Lankau, M. J. (2010). Formal mentoring programs: A Mentor-centric and longitudinal analysis. Journal of Management, 37(6), 1527-1557. 